\title{
Intelligent Control Technology for Natural Ventilation Used in Greenhouse
}

\author{
Yifei Chen and Wenguang Dai \\ College of Information and Electrical Engineering, China Agricultural University, \\ Haidian, Beijing, P.R. China 100083
}

\begin{abstract}
It is very important that the comfortable indoor climate is built for crop growing in greenhouse. To adjust the temperature and humidity, the natural ventilation operation and indoor airflow operation is necessary to be controlled. Depending on many researches and analysis for indoor climate of greenhouse, it is proved that the two main parameters, temperature and humidity in greenhouse, correlate with ventilation, and the relation equation is indicated tunambiguous. On the other hand, there is other research which indicates that the growth result of crop is affected by the ways of airflow in greenhouse as well as natural ventilation. For all of these factors, with advance control theory and intelligent control technology, the control system of natural ventilation is presented in this paper. The main point in the paper is that depending on replacement ventilation principle the natural ventilation will be controlled by driving the windows open. First, the ventilation model using in greenhouse is constructed specially using actuators for driving windows one by one, and control model is analyzed on the principle of natural ventilation too. It is present firstly that using fuzzy control method depending on the temperature indoor to drive windows to work is feasible. Then the system designing of driving windows is given, and the intelligentized controlling system for natural ventilation in greenhouse is constructed finally. According to the smart fuzzy calculating and crop growth need condition, the windows open angle can be controlled accurately with detecting indoor parameters such as temperature, humidity, $\mathrm{CO}_{2}$ density as well as outdoor temperature, sun light, wind and rain. Also, the characteristic and designing factors used in this control system, with one example, are shown in this paper.
\end{abstract}

Keywords: greenhouse indoor climate, natural ventilation, fuzzy control, driving window.

\section{Introduction}

It is fact that the natural ventilation in greenhouse has many advantages for crop growth. General speaking, the ventilation in greenhouse is forced to work by the machine like blower, so, there are many disadvantages clearly to see such as the wind force and direction cannot be controlled. On the other hand, not only the ventilation effect is affected, but the electrical energy cost is caused to increase. So, how about natural ventilation is valid used is the researching direction for greenhouse ventilation. 
The basic principles of natural ventilation are discussed in reference (T.Boulard et al.,1977; Roy J C et al.,2002; Boulard T et al.,2002), and the calculating model and simulation usind CFD are presented based on the indoor thermal pressure and outdoor wind pressure. Moreover, the general characteristic of parameters in greenhouse are stated too in reference (Xu Fang et al.,2005; Li Wiyi et al.,2005) as well as calculating model for ventilation. But how about making the control model for natural ventilation is not given as well as how to realize the control system. The ventilation control is discussed in reference (Gu Jinan et al.,2001). The author thinks that the indoor climate parameters like temperature, humidity, day lighting is assumptive inertial controlled factors, and the control model is given by time difference concept. But the control method is BANG-BANG with ON-OFF function, so control precision is lower and the veracity of dynamic adjusting for above parameters has been not proved.

As well as know, the dynamic adjusting for the indoor climate of greenhouse is very difficult for the fact that many parameters are strong coupling each other, and the control models are non-linear and complex. So, basing on this situation, it is hard to build the control system. According to the statement in reference (Roy J C et al.,2002), there is the basic change process that indoor air is mutual exchanged without air of greenhouse. We think this exchanging is taking place in parts of greenhouse, such as the enclosure, soil and windows. It is shown as Fig.1.

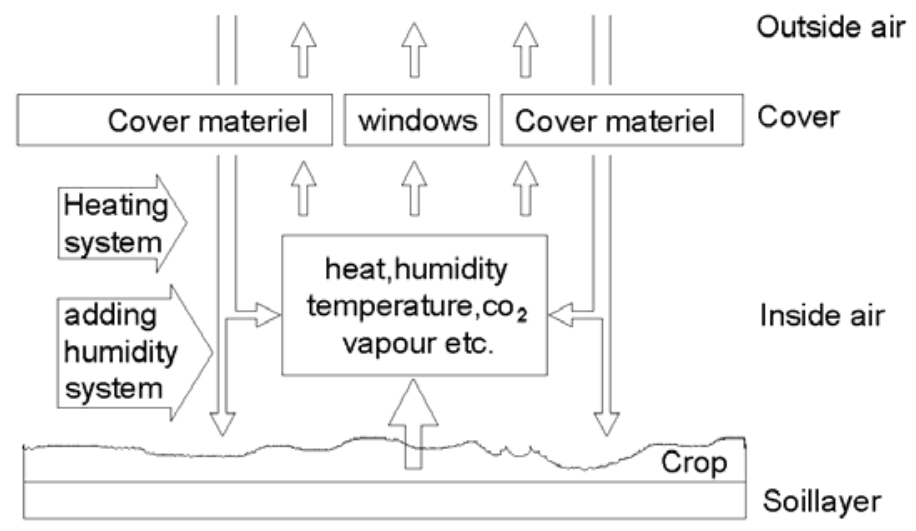

Fig. 1. Schematic representation of air exchange inside and outside of greenhouse

As Fig.1 showing, the exchanging is composed by two kinds: one is passive exchanging from greenhouse roof and wall etc. Another one is active exchanging from roof windows in greenhouse. That the roof windows are exactly controlled can resentful affect the indoor climate of greenhouse (Cecilia et al., 1995).

In this paper, for the windows controlling, the fuzzy control technology is used firstly, and the intelligent control system for greenhouse natural ventilation is built as following. 


\section{The Control System Model Designing for Natural Ventilation in Greenhouse}

\subsection{Building of Relation Model on Natural Ventilation in Greenhouse}

The temperature and relative humidity in greenhouse associate strongly with ventilation (Cecilia et al., 1995), and under the condition of natural ventilation, the relation equation of relative humidity and ventilation flux is as following:

$$
\boldsymbol{V}=g_{\text {vent }}\left(\chi_{\mathrm{a}}-\chi_{\mathrm{o}}\right) \quad\left(\mathrm{kg} \mathrm{m}^{-2} \mathrm{~s}^{-1}\right)
$$

Here, $\chi_{\mathrm{a}}$ means indoor relative humidity, $\chi_{0}$ means outdoor absolute humidity, $g_{v e n t}$ means ratio of ventilation, $V$ means bentilation flux density. It is presented that the relation is linear between ventilation flux and indoor humidity. On the other hand, if the roof window is as Fig.2, the relation equation between the temperature and ventilation flux, based on the vapor buoyancy effects, is as following:

$$
\phi_{\mathrm{b}, \text { front }}=C_{\mathrm{f}}(g \beta)^{1 / 2} \frac{L_{\mathrm{o}}}{3} H^{3 / 2}\left(\tilde{T}_{\mathrm{a}}-\tilde{T}_{\mathrm{o}}\right)^{1 / 2} \quad\left(\mathrm{~m}^{3} \mathrm{~s}^{-1}\right)
$$

Here, $\Phi_{\mathrm{b}, \text { front }}$ means ventilalation flux, $T_{a}$ and $T_{0}$ mean indoor and outdoor temperature respectively, $C_{f}$ means discharge coefficient, $\beta$ means thermal expansion coefficient of air, and $g$ means conductance to heat or mass transfer. $H$ means the roof window open height as Fig.2, and $H_{0}$ and $L_{0}$ stands for the size of roof window. So, the relation equation between the open angle and open height is as following:

$$
H=H_{\mathrm{o}}[\sin \psi-\sin (\psi-\alpha)]
$$

According to above equations, the conclusion can be got that if ventilation flux is controlled right, and than, the relative humidity and temperature in greenhouse also can be adjusted accordingly.

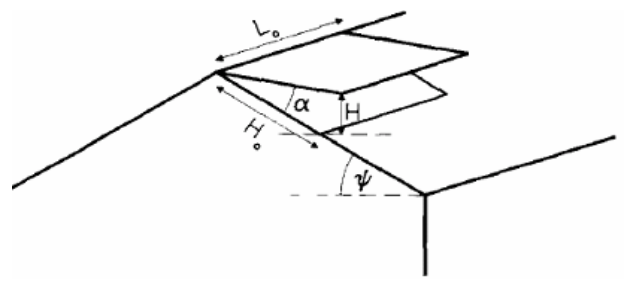

Fig. 2. Schematic representation of a roof greenhouse ventilator

\subsection{Control Model Structure}

Fig. 3 is shown the structure of intelligent control system for natural ventilation on greenhouse. There are some the windows driven by electrical actuators one by one designed in the tilted roof. The detecting parameters are included outdoor temperature 
To, outdoor lighting $L$, outdoor wind $W$ and rain $R$, whole which are input into MCU, main control unit. With the indoor detecting factors, and by the program calculating of computer in MCU, the electrical actuator is controlled to work, and ventilation flux of greenhouse is adjusted too.

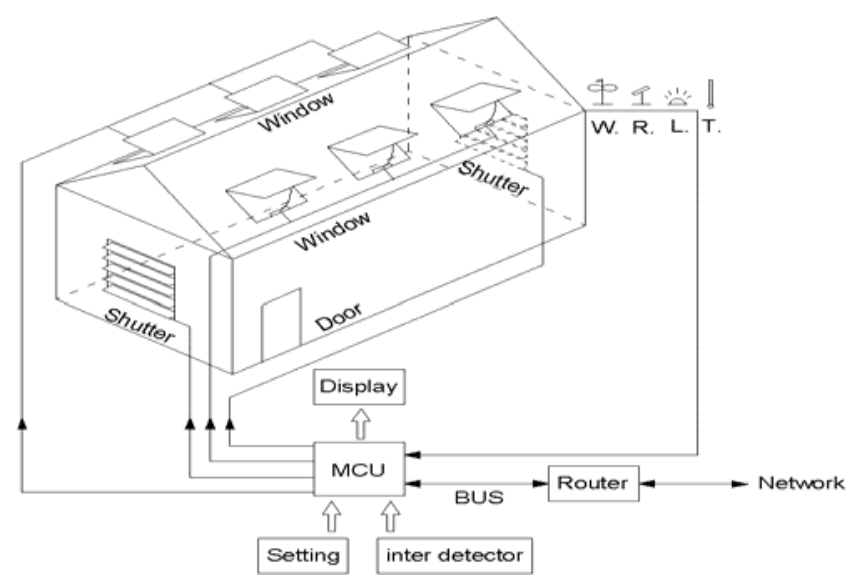

Fig. 3. Control model of nature ventilation used in greenhouse

\section{Fuzzy Control Technology for Nature Ventilation}

Certainly, the ventilation flux has been related with open angle of windows directly, and the angle has also a direct proportion with the stroke of actuators. For the control need of veracity and speediness, it is valid that fuzzy control technology is used for control window operation (Chen yifei et al.,2009). The fuzzy control system for driving windows in greenhouse is shown as Fig.4.

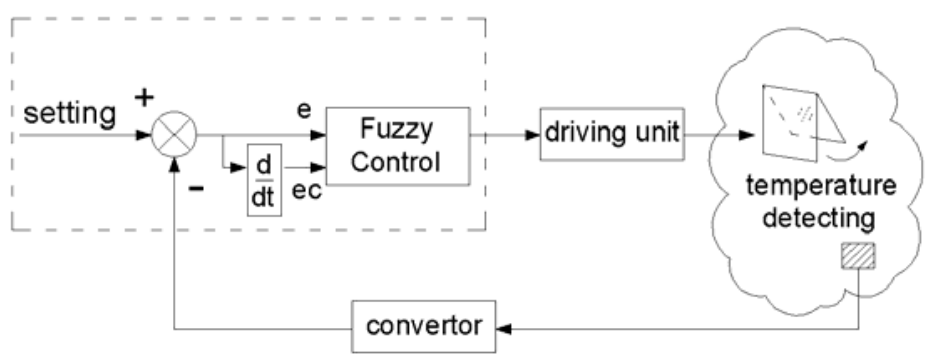

Fig. 4. Fuzzy control system model for natural ventilation

Where, setting value is the temperature that is known and at indoor pressure middle point, the output from driving unit is used to control stroke of actuators for window, such as rod length. 
Depending on the control window open area and type of rod actuators used, the total length of rod is thought as six segments to operate. By the testing, the relation of rod work delay time and window open angle is as Table 1.

Table 1. Rod segments setting opreation

\begin{tabular}{|c|c|c|}
\hline segment & $\begin{array}{c}\text { Window open } \\
\text { angle( }\end{array}{ }^{\circ}$ ) & $\begin{array}{c}\text { Actuator work } \\
\text { delay time(s) }\end{array}$ \\
\hline 1 & 5 & 3 \\
\hline 2 & 10 & 6 \\
\hline 3 & 15 & 9 \\
\hline 4 & 20 & 12 \\
\hline 5 & 25 & 15 \\
\hline 6 & 30 & 18 \\
\hline
\end{tabular}

Where, the parameters of the electrical rod actuator used is: $24 \mathrm{VDC}, 25 \mathrm{~W}$, type $\mathrm{S} 1$, by Mingardi srl. Italy, max.stroke $750 \mathrm{~mm}$, operation speed $20 \mathrm{~mm} / \mathrm{s}$ with load. The size of roof window is $1200 \mathrm{~mm} * 750 \mathrm{~mm}$.

All of parameters of $E, E C, U$ in fuzzy system are defined as error of temperature 、 the change ratio of the error、 the run delay time of actuators, and their language values are definite as: $\{\mathrm{PB}, \mathrm{PM}, \mathrm{PS}, \mathrm{PO}, \mathrm{NO}, \mathrm{NS}, \mathrm{NM}, \mathrm{NB}\}$.Therefore, the fuzzy control regular table is built (Chen yifei et al.,2009).

The following Fig.5 and Fig.6 are respective shown that the test situation and the electrical rod actuators are used to drive the windows of greenhouse for natural ventilation.

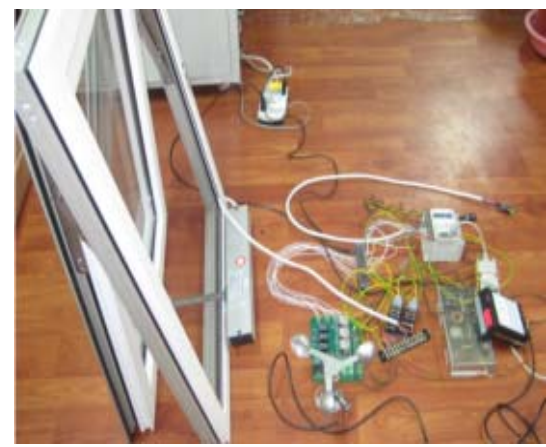

Fig. 5. Test of driving window with fuzzy control

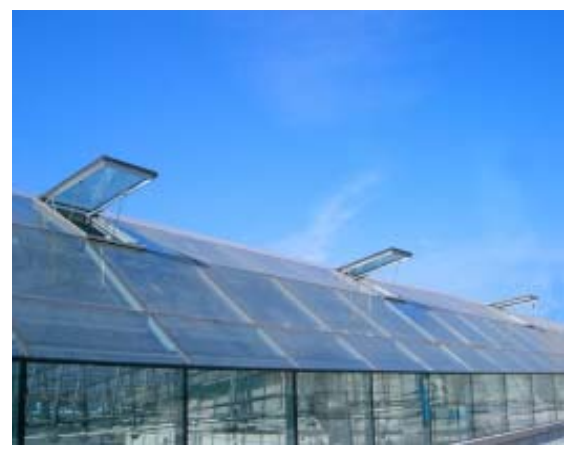

Fig. 6. The electrical rod actuators used in greenhouse window driving 


\section{Conclusion}

For the need of natural ventilation in greenhouse, exact ventilation control will be regarded. According to the electrical rod actuator using to drive the window of greenhouse, the relation both open angle of window and rod length is established in this paper. Finally, the fuzzy control technology is used in the control system, and establishing the control strategy that the veracity and speediness of ventilation control can be achieved by control window open area with some limited conditions. After testing, it is proved that the ventilation control effect is improved with fuzzy control system being built, and the intelligent control is developed obviously. Moreover, the control model is simply and the intelligent control network is reached too. There are some advantages for application promotion, such as long distance monitoring and controlling for greenhouse etc. Of course, in next step, some points in this control will be researched like the smart control for indoor air flow organizing, and energy-saving potential control as well as the effect testing for different crops.

\section{References}

Boulard, T., Papadakis, G., et al.: Air Flow and Associated Sensible Heat Exchanges in a Naturally vVentilated Greenhouse. Agricultural and Forest Meteorology 88, 111-119 (1977)

Roy, J.C., Boulard, T., Kittas, C., et al.: Convective and Ventilation Transfers in Greenhouses, Part 1:the greenhouse considered as a perfectly stirred tank. Biosystems Engineering 83(1), 1-20 (2002)

Boulard, T., Kittas, C., Roy, J.C., et al.: Convective and Ventilation Transfers in Greenhouses Part 2: determination of the distributed greenhouse climate. Biosystems Engineering 83(2), 129-147 (2002)

Fang, X., Linbin, Z., et al.: Modeling and Simulation of Subtropical Greenhouse Microclimate in China. Transactions of the Chinese Society for Agricultural Machinery 36(11), 102-105 (2005) (in Chinese)

Wiyi, L., Zhaoli, 1., et al.: Research on Agricultural Greenhouse Micoclimate and Analysis of Theoretical Model. Transactions of the Chinese Society for Agricultural Machinery 36(5), 137-140 (2005) (in Chinese)

Jinan, G., Hanping, M.: A Mathematical Model on Intellingent Control of Greenhouse Environment. Transactions of the Chinese Society for Agricultural Machinery 32(6), 63-65 (2001) (in Chinese)

Stanghellini, C., de Jong, T.: A Model of Humidity and Its Application in a Greenhouse. Agricultural and Forest Meteorology 76, 129-148 (1995)

Yifei, C., Ku, W., Wenguang, D.: Natural Ventilation Control System by Fuzzy Control Technology. Accept by International Conference on Intelligent Networks and Intelligent Systems (ICINIS 2009), Tianjin, China (November 2009) 